\title{
Defective regulation of triglyceride metabolism by insulin in the liver in NIDDM
}

\author{
R. M almström ${ }^{1}$, C. J . Packard², M. Caslake'2, D. B edford², P. Stewart², H . Y ki-J ärvinen ${ }^{1}$, J. Shepherd², \\ M.-R . Taskinen ${ }^{1}$ \\ ${ }^{1}$ Department of Medicine, University of Helsinki, Helsinki, Finland \\ ${ }^{2}$ Department of Pathological Biochemistry, Royal Infirmary, Glasgow, Scotland, UK
}

Summary Insulin administration to healthy subjects inhibits the production of very low density lipoprotein (VLDL)1 (Svedbergs flotation (Sf) rate 60400 ) without affecting that of VLDL2 (Sf 20-60) subclass. This study was designed to test whether this hormonal action is impaired in non-insulin-dependent diabetes mellitus (NIDDM). We studied six men with NIDDM (age $53 \pm 3$ years, body mass index $27.0 \pm 1.0 \mathrm{~kg} / \mathrm{m}^{2}, \quad$ plasma triglycerides $1.89 \pm$ $0.22 \mathrm{mmol} / \mathrm{l}$ ) during an $8.5 \mathrm{~h}$ infusion of saline (control) and then in hyperinsulinaemic (serum insulin $\sim 540 \mathrm{pmol} / \mathrm{l}$ ) conditions during $8.5 \mathrm{~h}$ infusions of glucose and insulin to give either hyper- and normoglycaemic conditions. $\left[3-{ }^{2} \mathrm{H}\right]$-leucine was used as tracer and kinetic constants derived using a non-steadystate multicompartmental model. Compared to the control study, patients with NIDDM reduced
VLDL1 apo B production by only $3 \pm 8 \%$ after $8.5 \mathrm{~h}$ of hyperinsulinaemia (701 \pm 102 vs $672 \pm 94 \mathrm{mg} /$ day respectively, NS) in hyperglycaemic conditions and by $9 \pm 21 \%$ under normoglycaemic conditions $(603 \pm$ $145 \mathrm{mg} /$ day). In contrast, in normal subjects insulin induced a $50 \pm 15 \%$ decrement in VLDL1 apo B production $(p<0.05)$. Direct synthesis of VLDL2 apo B in patients with NIDDM was not markedly affected by insulin. We conclude that a contributory factor to hypertriglyceridaemia in NIDDM is the inability of insulin to inhibit acutely the release of VLDL1 from the liver, despite efficient suppression of serum nonesterfied fatty acids. [Diabetologia (1997) 40: 454462]

Keywords Apolipoprotein B, stable isotopes, insulin resistance, non-esterified fatty acids, cholesterol.
Features of diabetic dyslipidaemia in non-insulin-dependent diabetes mellitus (NIDDM), such as a low HDL cholesterol concentration, the preponderance of small dense LDL and postprandial fat intolerance are considered to be metabolic consequences of elevated plasma triglycerides [1]. The mechanism underlying hypertriglyceridaemia in NIDDM is still

Received: 7 October 1996 and in revised form: 24 December 1996

Corresponding author: M.-R. Taskinen, M.D., Department of Medicine, Division of Endocrinology and Diabetology, Helsinki University Central Hospital, Haartmaninkatu 4, FIN00290 Helsinki, Finland

A bbreviations: GC-MS, Gas chromatography-mass spectrometry; FCR, fractional catabolic rate; Sf, Svedberg flotation rate; LPL, lipoprotein lipase; NIDDM, non-insulin-dependent diabetes mellitus. unclear. A majority of studies indicate that the elevation of plasma triglycerides in NIDDM result from an overproduction of VLDL triglyceride [2,3] and apo B $[4,5]$ but it is unclear and a matter of controversy whether the increased production of VLDL particles is driven by a direct effect of hyperinsulinaemia or is a consequence of defective suppression of VLDL production by insulin [1]. In healthy subjects acute insulin administration suppresses VLDL apo B production [6-8]. Data on the suppression of VLDL production by insulin in insulin resistant states are controversial. Lewis et al. [6] showed an impaired suppression of VLDL apo B production in obese subjects while Cummings et al. [9] did not find any defect in the ability of insulin to suppress VLDL apo B production in patients with NIDDM.

Two major subclasses of VLDL particles are recognised, large triglyceride-rich VLDL1 particles 
Table 1. Physical and biochemical characteristics of the subjects

\begin{tabular}{lllllllll}
\hline Subject & $\begin{array}{l}\text { Age } \\
(\text { years })\end{array}$ & $\begin{array}{l}\text { Weight } \\
(\mathrm{kg})\end{array}$ & $\begin{array}{l}\text { BMI } \\
\left(\mathrm{kg} / \mathrm{m}^{2}\right)\end{array}$ & $\begin{array}{l}\text { Body fat } \\
(\%)\end{array}$ & $\begin{array}{l}\mathrm{HbA}_{1 \mathrm{c}} \\
(\%)\end{array}$ & $\begin{array}{l}\text { Triglycerides } \\
(\mathrm{mmol} / \mathrm{l})\end{array}$ & $\begin{array}{l}\text { Total chol } \\
(\mathrm{mmol} / \mathrm{l})\end{array}$ & $\begin{array}{l}\text { HDL chol } \\
(\mathrm{mmol} / \mathrm{l})\end{array}$ \\
\hline 1 & 51 & 91.7 & 28.3 & 28.1 & 7.8 & 1.39 & 3.00 \\
2 & 54 & 100.0 & 29.9 & 30.8 & 6.6 & 2.19 & 5.33 \\
3 & 45 & 94.6 & 27.7 & 27.1 & 9.3 & 2.00 & 4.95 \\
4 & 63 & 75.6 & 22.8 & 21.5 & 7.8 & 1.18 & 4.30 & 0.85 \\
5 & 59 & 85.2 & 27.8 & 28.4 & 9.0 & 2.35 & 5.36 \\
6 & 48 & 79.0 & 25.5 & 25.2 & 7.1 & 2.25 & 4.26 \\
NIDDM & $53 \pm 3$ & $87.7 \pm 3.8$ & $27.0 \pm 1.0$ & $26.9 \pm 1.3$ & $7.9 \pm 0.4$ & $1.89 \pm 0.22$ & $4.53 \pm 0.36$ & 1.04 \\
Control subjects & $51 \pm 3$ & $86.5 \pm 3.9$ & $26.3 \pm 0.7$ & $22.4 \pm 1.8$ & $5.4 \pm 0.1^{\mathrm{a}}$ & $1.42 \pm 0.18$ & $5.23 \pm 0.24$ & $1.20 \pm 0.07$ \\
\hline
\end{tabular}

Data are mean of the fasting measurements on two turnover days; chol, cholesterol; ${ }^{a} p<0.001$ as compared to patients with NIDDM, $n=7$ for the control subjects

with a Svedberg flotation rate (Sf) of 60-400 and smaller and more dense VLDL2 particles of Sf 20 60 . We have recently shown that in healthy subjects acute hyperinsulinaemia suppresses VLDL1 apo B production but has no effect on direct VLDL2 apo B synthesis [8]. In NIDDM the VLDL spectrum is characterised by an abundance of VLDL1 particles [3] indicating a specific defect in the metabolic behaviour of this subclass rather than a general defect in VLDL metabolism. There is, however at present no information on the effect of acute hyperinsulinaemia on VLDL subclasses in NIDDM.

This study was designed to test the hypothesis that the effect of acute hyperinsulinaemia on VLDL1 apo $B$ production is impaired in NIDDM. Apo B turnovers using stable isotope $\left[3-{ }^{2} \mathrm{H}\right]$ leucine were therefore performed in six men with NIDDM and in seven normal subjects during an infusion of saline. Data on the effect of insulin on VLDL apo B kinetics in normal subjects has recently been reported [8]. The effect of insulin on VLDL subclass kinetics in patients with NIDDM was determined both under normoand hyperglycaemic conditions to determine whether hyperglycaemia affects VLDL apo B kinetics independent of the action of insulin.

\section{Materials and methods}

Subjects. Six men with NIDDM participated in the studies. The duration of diabetes was $6 \pm 2$ years. None of the subjects had clinical evidence of cardiac, hepatic, renal or endocrine disease other than diabetes. The patients were treated with diet alone (subjects 3 and 4) or diet and glibenclamide (subject 2 and 6) or with a combination of diet, glibenclamide and biguanide (subjects 1 and 5). Medication was continued throughout the studies except on the turnover days. The patients took no other agent known to affect lipid or glucose metabolism. Physical and biochemical characteristics of the subjects are shown in Table 1. For comparison we have also presented values for a previous study in seven normal subjects [8].

The purpose, nature and potential risks of the studies were explained to the subjects before their written informed consent was obtained. The study protocol was approved by the ethical committee of the Helsinki University Hospital.
Study design. All patients with NIDDM participated in random order in two turnover studies performed a) during an infusion of saline and b) during a hyperglycaemic hyperinsulinaemic clamp. The studies were performed with a 1-2 month interval between them. Five patients with NIDDM participated in a third turnover study during a normoglycaemic hyperinsulinaemic clamp again after a 1-2 month interval. Normal subjects participated in two turnover studies a) during an infusion of saline and b) during a normoglycaemic hyperinsulinaemic clamp. Subjects were instructed to ingest an isocaloric, weight maintaining diet for 1 month before and during the study period. They were asked to record their dietary intake for $24 \mathrm{~h}$ before the first admission and to replicate this diet before the other admissions. The clinical and laboratory work was done in Helsinki, while the gas-chromatography mass spectrometry (GC-MS) and kinetic analyses were performed in Glasgow.

Hyperglycaemic hyperinsulinaemic clamp. The patients were admitted to the metabolic ward at the Helsinki University Central Hospital at 07.30 hours. An indwelling cannula was inserted in an antecubital vein for infusions and a second cannula was inserted retrogradely into a heated hand vein to obtain arterialized venous blood for blood sampling. At 0 min a primedcontinuous infusion of insulin (Actrapid Human; Novo Nordisk, Copenhagen, Denmark) was started (rate of continuous infusion $1 \mathrm{mU} \cdot \mathrm{kg}^{-1} \cdot \mathrm{min}^{-1}$ ). Plasma glucose was maintained at its fasting level by a variable rate infusion of $20 \%$ glucose [10]. The infusion rate was determined empirically based on plasma glucose measurements, which were performed every 5-10 min from arterialized venous blood. Glucose infusion rate during the hyperinsulinaemia was calculated from the mean values of the second hour glucose infusion rate after correcting for changes in the glucose pool size [10]. The subjects were fasting until 17.00 hours when they were served a meal. A light evening snack was served at 20.00 hours. The subjects then remained fasting until 08.30 hours the next morning when the last blood sample was drawn.

Normoglycaemic hyperinsulinaemic clamp. Before the normoglycaemic hyperinsulinaemic study the patients were admitted to the metabolic ward at 08.30 hours. Plasma glucose concentrations were normalized using an overnight insulin (Actrapid Human; Novo Nordisk) infusion $(\sim 0.4 \mathrm{mU} \cdot \mathrm{kg} \cdot \mathrm{min})$, which was started at 22.00 hours and adjusted according to the algorithm of Mokan and Gerich [11]. The blood glucose concentration was measured at 30-60 min intervals between 22.00 and 08.30 hours. At 0 min (08.00 hours) a normoglycaemic hyperinsulinaemic clamp was started and performed as the hyperglycaemic clamp described above. 
Control study with saline infusion. During the control study saline was infused at a rate of $200 \mathrm{ml} / \mathrm{h}$. This equaled approximately the volume of insulin and glucose infusions during the clamp study.

M easurement of apo B turnover. Apo B turnover was measured on each study occasion (saline control study, hyper- and normoglycaemic clamp studies) starting after a 30-min infusion of saline or insulin at 09.00 hours. All timings for the turnovers are related to the start ( $0 \mathrm{~min}=08.30$ hours $)$ of the saline or insulin infusion. A bolus injection of $\left[3-{ }^{2} \mathrm{H}\right]$ leucine $(\mathrm{C} / \mathrm{D} / \mathrm{N}$ Isotopes Inc., Vaudreuil, Quebec: $7 \mathrm{mg} / \mathrm{kg}$ of body weight) dissolved in saline was given at $30 \mathrm{~min}$. Blood samples for the determination of plasma $\left[3-{ }^{2} \mathrm{H}\right]$ leucine concentration were taken immediately before the bolus injection and at $32,34,36,38$, $40,42,45,50,60,75 \mathrm{~min}$ and $1.5,2.5,3.5,4.5,6.5$, and $8.5 \mathrm{~h}$. To measure VLDL1 and VLDL2 apo B $\left[3-{ }^{2} \mathrm{H}\right]$ leucine enrichment, blood samples were taken before tracer bolus administration and at 45, 60, 75, 90, 105, 120, 150 and $180 \mathrm{~min}$ and 3.5, 4.5, 5.5, 6.5, 7.5, 8.5 and $24 \mathrm{~h}$. Apo B mass concentration of plasma VLDL1 and VLDL2 fractions were determined three times during the study period at $30 \mathrm{~min}, 4.5 \mathrm{~h}$ and $8.5 \mathrm{~h}$.

Isolation of lipoproteins. VLDL1 and VLDL2 were isolated from plasma by cumulative flotation gradient ultracentrifugation using a six-step discontinuous salt gradient as previously described $[12,13,14]$. Pool sizes for apo B were calculated from the product of plasma volume (assumed to be $4.5 \%$ of body weight) times the plasma concentration of apo $B$ in VLDL1 and VLDL2. The leucine content of the apo B pool was calculated from the amino acid composition of apo B [15].

P reparation and analysis of leucine enrichment in apo B. Apo B in isolated lipoprotein fractions was precipitated by isopropanol [16]. Equal volumes of the lipoprotein fraction and isopropanol were mixed and stored at $+4{ }^{\circ} \mathrm{C}$ overnight. The following morning, samples were centrifuged at $3000 \mathrm{rev} / \mathrm{min}$ for $30 \mathrm{~min}$ at $+4^{\circ} \mathrm{C}$ and the infranatant containing isopropanol soluble proteins under the thin apo B layer was removed. The apo B pellicle was then delipidated with ethanol-diethylether, dried and subsequently hydrolysed with $6 \mathrm{~mol} / \mathrm{l} \mathrm{HCL}$ at $110^{\circ} \mathrm{C}$ for $22-24 \mathrm{~h}$. To determine plasma leucine enrichments, proteins were precipitated using trichloroacetic acid as described [17]. The method employed for the analysis of [3$\left.{ }^{2} \mathrm{H}\right]$ leucine enrichment in protein hydrosylates and plasma amino acids has been described in detail elsewhere [17].

Kinetic analysis of VLDL 1 and VLDL 2 apo B. Tracer/tracee ratios and apo $\mathrm{B}$ masses were used to derive kinetic rate constants describing the production and catabolism of VLDL1 and VLDL2 apo B. The data were analysed with the CONSAM program [18] using the non-steady-state multicompartmental model shown in Figure 1. The model had the following features. First, plasma leucine kinetics were described by a four compartment subsystem. The present experimental design did not allow determination of all the rate constants for plasma leucine. Some were fixed (Fig.1) based on values derived from previous studies on long-term (14 day) data in a large group of subjects [17]. Others were allowed to vary to adjust the plasma leucine curve between individuals. Input of leucine into VLDL1 and VLDL2 apo B occurred from compartment 2 via a delay component (compartment 5 ). The delay was set at $0.5 \mathrm{~h}$ initially but this value was adjusted if required by the data. VLDL1 was modelled as a short delipidation chain in line with previously published systems [17] and a remnant compartment was included for subjects who required it to obtain a good fit. The default was to set $\mathrm{k}_{8,6}$ to zero. Similarly, in

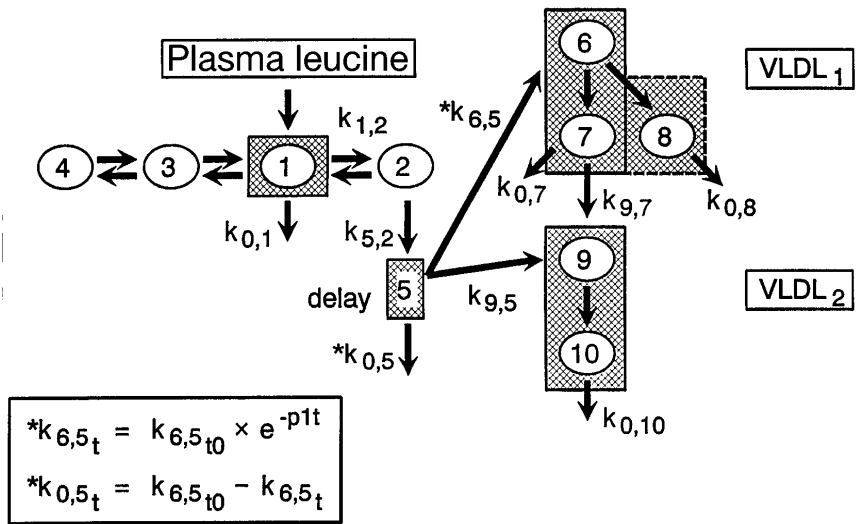

Fig. 1. Multicompartmental model of VLDL1 and VLDL2 apo B metabolism. Plasma leucine was modelled as a fourcompartment sub-system on the basis of previous longer term experiments. $\mathrm{k}_{0,1}, \mathrm{k}_{1,2}, \mathrm{k}_{5,2}$ were adjustable. $\mathrm{k}_{3,4}, \mathrm{k}_{4,3}, \mathrm{k}_{3,1}, \mathrm{k}_{1,3}$ and $\mathrm{k}_{2,1}$ were fixed at population mean values of $0.0275,0.181$, 2.528, 0.0469 and 3.012, respectively. $\mathrm{k}_{6,5}, \mathrm{k}_{9,5}$ and $\mathrm{k}_{0,5}$ represent the distribution of apo B production. They are a fraction of 1.0, $\mathrm{k}_{0,5}$ is 0 when there is no change in $\mathrm{k}_{6,5}$ with time. If $\mathrm{k}_{6,5}$ decreases with time in the non-steady-state situation $\mathrm{k}_{0,5}$ compensates for this and allows $\mathrm{k}_{9,5}$ to remain constant. To reduce the number of unknowns a number of dependent constants were defined $\mathrm{k}_{7,6}=\mathrm{k}_{9,7} ; \mathrm{k}_{0,8}=\mathrm{k}_{8,6} ; \mathrm{k}_{10,9}=\mathrm{k}_{0,10}$. The equation permitting the decrease in $\mathrm{k}_{6,5}$, the VLDL1 apo $\mathrm{B}$ input, with time is given. An exponential function was used with constant $\mathrm{p} 1$ representing the fractional decrease in input per unit time (hours). $t$ denotes the value at time $t, t 0$ the value at zero time

most patients $\mathrm{k}_{0,7}$ was not required and this was set to zero for baseline and clamp studies. If $\mathrm{k}_{0,7}$ was needed to generate a satisfactory fit in either turnover, it was fixed to the same value in the other study. Input of apo B occurred at compartment 6 in VLDL1 and compartment 9 in VLDL2. VLDL2 was modelled as a short delipidation chain with a single output.

In normal subjects studied previously [8], the concentration of VLDL1 apo B fell markedly over the course of the acute hyperinsulinaemia and the model had to take account of this nonsteady-state situation. Thus $\mathrm{k}_{6,5}$ was permitted to decrease with time according to the equation shown in Figure 1. Using this approach an excellent fit was obtained for both the tracer data and the change in mass in VLDL1. The same model was applied to current turnovers. Permitting VLDL2 apo B production $\left(\mathrm{k}_{9,5}\right)$ to vary with time did not result in an improved fit to the observed data. This parameter and $\mathrm{k}_{9,7}, \mathrm{k}_{0,10}, \mathrm{k}_{1,2}$ and $\mathrm{k}_{0,1}$ were allowed to vary freely between turnovers but were not made a function of time. This model is based on a compartmental model developed by Björkegren et al. [19] to describe the non-steady-state changes in VLDL apo B metabolism.

The experimental tracer/tracee ratios were weighted within CONSAM by applying a standard deviation of approximately $4 \times 10^{-5}$ to the data. This represented a coefficient of variation of about $1 \%$ for peak ratios in VLDL1 and VLDL2 apo B [3$\left.{ }^{2} \mathrm{H}\right]$ leucine. A co-efficient of variation of $5 \%$ was applied to the apo B pool sizes. The mean tracer masses in VLDL1 and VLDL2 apo B are presented in Figure 2.

A nalytical methods. Plasma glucose concentrations were measured in duplicate using the glucose oxidation method (Beckman Glucose Analyzer II; Beckman Instruments, Fullerton, Calif., USA) [20]. $\mathrm{HbA}_{1 \mathrm{c}}$ was measured with ion exhange high performance liquid chromatography (Bio-Rad, 

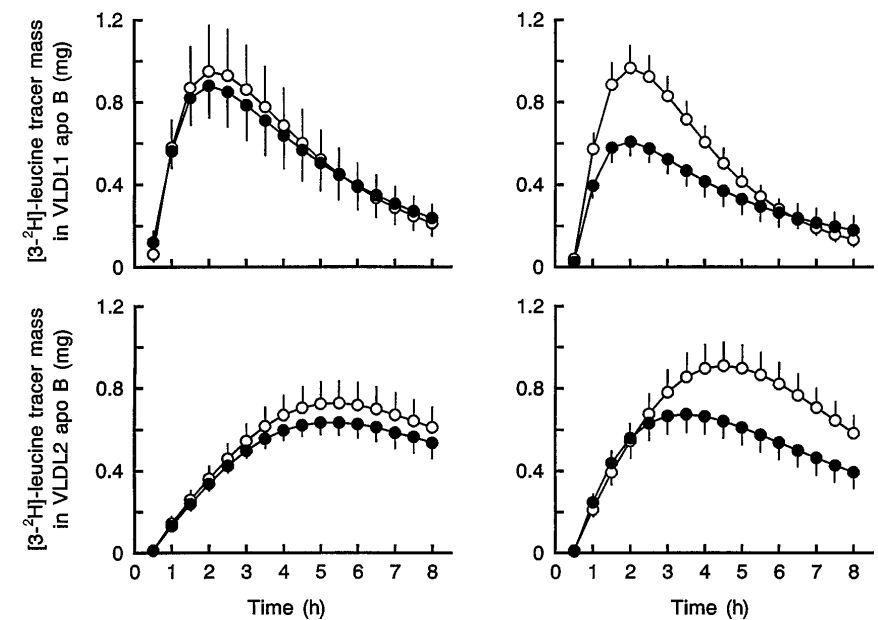

Fig. 2. $\left[3-{ }^{2} \mathrm{H}\right]$ leucine tracer mass $(\mathrm{mg})$ in VLDL1 (upper panel) and VLDL2 (lower panel) apo B in patients with NIDDM (under hyperglycaemic conditions) (left) and in normal subjects (right) during saline () and insulin (O) infusions. Bars represent SEM

Richmond, Calif., USA) [21]. Serum free insulin concentrations were determined by double antibody radioimmunoassay (Pharmacia Insulin RIA Kit; Pharmacia, Uppsala, Sweden) after precipitation with polyethylene glycol. Concentrations of cholesterol and triglyceride (Hoffman-La Roche kits Nos. 0736805 and 0736642, respectively Basel, Switzerland) were measured enzymatically in an automated Cobas Mira analyzer (Basel, Switzerland). Serum NEFA were quantified by the fluorometric method of Miles et al. [22]. Serum glycerol was determined by an enzymatic spectrophotometric method [23]. The concentration of proteins in isolated lipoprotein fractions were determined according to Kashyap et al. [24]. Apo E phenotyping was done from serum by isoelectric focusing [25].

$\mathrm{O}$ ther measurements. The percent body fat was determined using a single frequency bioelectrical impedance device (BioElectrical Impedance Analyzer System, Model \#BIA-101A, Mf.Clemens, Mich., USA) [26].

\section{Statistical analysis}

All data are expressed as the mean \pm SEM. Statistical comparisons between the study occasions were made with paired Student's t-test and between the patients with NIDDM and normal subjects with unpaired Student's t-test. Repeated measures analysis of variance (ANOVA) was used to evaluate whether there was any significant change in the measured parameters during an insulin or a saline infusion. Variables with skewed distributions (plasma triglycerides) were logarithmically transformed before statistical comparisons. P-values less than 0.05 were considered to be statistically significant. Data analysis was performed using the SYSTAT statistical package (SYSTAT Inc., Evanston, Ill., USA).

\section{Results}

Serum free insulin, plasma glucose concentrations and glucose infusion rates. In patients with NIDDM the plasma glucose concentration (Fig. 3) was maintained
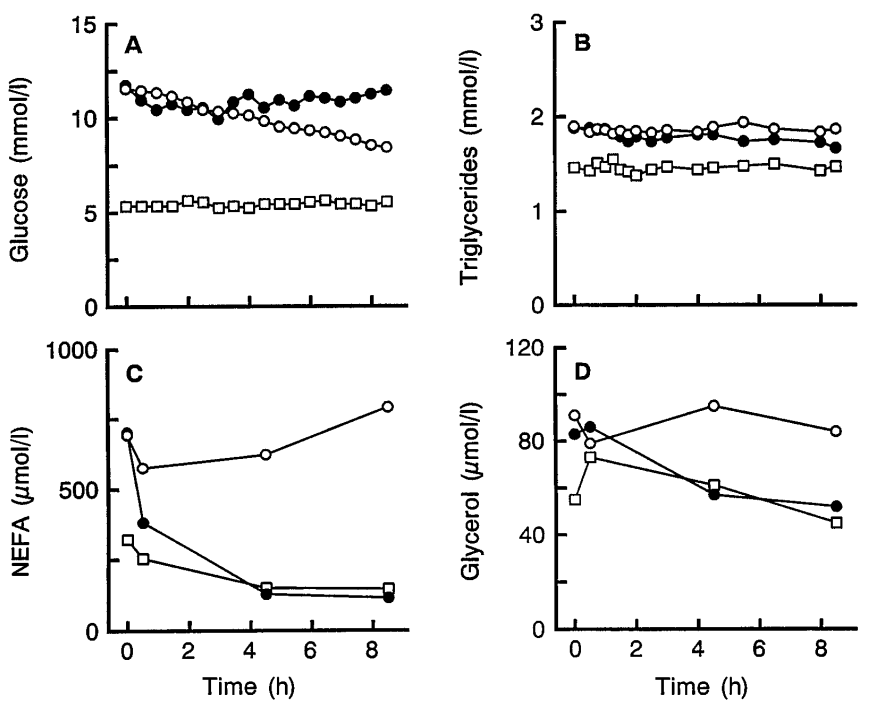

Fig. 3A-D. Plasma concentration of glucose, triglycerides, NEFA and glycerol during saline infusion $(O)$ and insulin infusion during the hyperglycaemic $(\bigcirc)$ and normoglycaemic $(\square)$ clamp studies

at its fasting level during the hyperglycaemic $(10.7 \pm$ $0.8 \mathrm{mmol} / \mathrm{l})$ and normoglycaemic $(5.4 \pm 0.1 \mathrm{mmol} / \mathrm{l})$ clamp. During the saline infusion the plasma glucose concentration averaged $9.9 \pm 0.8 \mathrm{mmol} / \mathrm{l}$. Serum free insulin averaged $526 \pm 31 \mathrm{pmol} / \mathrm{l}$ during the hyperglycaemic clamp, $551 \pm 43 \mathrm{pmol} / \mathrm{l}$ during the normoglycaemic clamp and $47 \pm 5 \mathrm{pmol} / \mathrm{l}$ during the infusion of saline. Glucose infusion rate averaged $17.8 \pm$ $2.8 \mu \mathrm{mol} \cdot \mathrm{kg}^{-1} \cdot \mathrm{min}^{-1}$ during the hyperglycaemic clamp and $18.3 \pm 6.1 \mu \mathrm{mol} \cdot \mathrm{kg}^{-1} \cdot \mathrm{min}^{-1}$ during the normoglycaemic clamp.

Plasma lipids, NE FA and glycerol concentrations. In the NIDDM patients plasma triglyceride (Fig.3) did not change during the infusion of insulin under hyperglycaemic or normoglycaemic conditions or during the infusion of saline although the starting value on the normoglycaemic clamp was $23 \%$ lower. Plasma cholesterol concentration decreased during both the hyperglycaemic clamp (from $4.45 \pm 0.35$ to $4.01 \pm$ $0.33 \mathrm{mmol} / \mathrm{l}, \mathrm{p}<0.05$ ), and during the normoglycaemic clamp (from $4.27 \pm 0.37$ to $3.99 \pm 0.31 \mathrm{mmol} / \mathrm{l}$, $p<0.05)$ but remained unchanged during the infusion of saline. Fasting NEFA (Fig. 3) were comparable at the initiation of the hyperglycaemic clamp and the saline infusion study but significantly reduced after the overnight insulin infusion (Fig. 3). During both insulin infusions NEFA declined rapidly, from $702 \pm 78$ at $0 \mathrm{~h}$ to $115 \pm 12 \mu \mathrm{mol} / 1$ at $8.5 \mathrm{~h}, \mathrm{p}<0.01$ under hyperglycaemic conditions and from $321 \pm 13$ to $146 \pm$ $20 \mu \mathrm{mol} / 1, \mathrm{p}<0.01$ under normoglycaemic conditions. No significant change of serum NEFA occurred during infusion of saline (Fig. 3). Serum glycerol decreased during the hyperglycaemic clamp (from $83 \pm 8$ to $52 \pm 8 \mu \mathrm{mol} / \mathrm{l}, \mathrm{p}<0.05)$ and during the 
Table 2. VLDL1 apo B pool size

\begin{tabular}{|c|c|c|c|c|c|c|c|c|c|}
\hline \multirow[t]{2}{*}{ Subject } & \multicolumn{3}{|c|}{ Saline infusion } & \multicolumn{3}{|c|}{ Insulin infusion $\mathrm{A}$} & \multicolumn{3}{|c|}{ Insulin infusion B } \\
\hline & $0.5 \mathrm{~h}$ & $4.5 \mathrm{~h}$ & $8.5 \mathrm{~h}$ & $0.5 \mathrm{~h}$ & $4.5 \mathrm{~h}$ & $8.5 \mathrm{~h}$ & $0.5 \mathrm{~h}$ & $4.5 \mathrm{~h}$ & $8.5 \mathrm{~h}$ \\
\hline 1 & 93 & 113 & 83 & 77 & 78 & 95 & 46 & 61 & 36 \\
\hline 3 & 108 & 106 & 89 & 136 & 147 & 136 & 70 & 145 & 122 \\
\hline 4 & 35 & 33 & 39 & 32 & 30 & 42 & 12 & 11 & 17 \\
\hline 5 & 140 & 138 & 160 & 56 & 56 & 50 & & & \\
\hline 6 & 98 & 105 & 107 & 127 & 116 & 121 & 113 & 133 & 155 \\
\hline
\end{tabular}

Insulin infusion A under hyperglycaemic conditions in patients with NIDDM; Insulin infusion B under normoglycaemic conditions in patients with NIDDM; ${ }^{a} p<0.05$ vs respective value during hyperglycaemic clamp. ${ }^{b} p<0.05$ vs value at $0.5 \mathrm{~h}$

Table 3. VLDL2 apo B pool size

\begin{tabular}{|c|c|c|c|c|c|c|c|c|c|}
\hline \multirow[t]{2}{*}{ Subject } & \multicolumn{3}{|c|}{ Saline infusion } & \multicolumn{3}{|c|}{ Insulin infusion A } & \multicolumn{3}{|c|}{ Insulin infusion B } \\
\hline & $0.5 \mathrm{~h}$ & $4.5 \mathrm{~h}$ & $8.5 \mathrm{~h}$ & $0.5 \mathrm{~h}$ & $4.5 \mathrm{~h}$ & $8.5 \mathrm{~h}$ & $0.5 \mathrm{~h}$ & $4.5 \mathrm{~h}$ & $8.5 \mathrm{~h}$ \\
\hline 1 & 154 & 130 & 151 & 121 & 91 & 80 & 108 & 78 & 85 \\
\hline 4 & 102 & 97 & 112 & 98 & 87 & 86 & 74 & 53 & 63 \\
\hline 5 & 304 & 245 & 285 & 210 & 199 & 189 & & & \\
\hline 6 & 140 & 108 & 138 & 133 & 103 & 115 & 131 & 85 & 111 \\
\hline Control subjects & $159 \pm 24$ & $144 \pm 9$ & $163 \pm 17$ & $122 \pm 17$ & $129 \pm 24$ & $133 \pm 22$ & & & \\
\hline
\end{tabular}

Insulin infusion A under hyperglycaemic conditions in patients with NIDDM; Insulin infusion B under normoglycaemic conditions in patients with NIDDM; ${ }^{\mathrm{a}} \mathrm{p}<0.01$ vs value at $0.5 \mathrm{~h}$

normoglycaemic clamp (from $58 \pm 5$ to $47 \pm 3 \mu \mathrm{mol} / \mathrm{l}$, $p<0.05)$, but did not change significantly during the saline infusion $(91 \pm 11$ at $0 \mathrm{~h}$ vs $84 \pm 3 \mu \mathrm{mol} / \mathrm{l}$ at $8.5 \mathrm{~h}, \mathrm{NS})$.

VLDL 1 and VLDL 2 apo B pool sizes. During the control saline infusion the VLDL1 apo B pool was constant at a mean of about $110 \mathrm{mg}$ (Table 2). It was at a similar value $0.5 \mathrm{~h}$ into the insulin infusion in the hyperglycaemic clamp (106 $\pm 26 \mathrm{mg})$ and continued administration of the hormone did not depress the concentration of this subfraction, in contrast to the findings in normal subjects (cf Table 2 and [8]). At the beginning of the hyperinsulinaemic, normoglycaemic study the pool of VLDL1 apo B was substantially reduced $(69 \pm 19 \mathrm{mg}, p<0.05)$ compared to the other two turnovers and if anything tended to increase during the period of the infusion. VLDL2 apo B pool size was stable during the saline infusion falling $9 \%$ (NS) over the $8.5 \mathrm{~h}$ period (Table 3 ). During the hyperinsulinaemic, hyperglycaemic clamp there was a $15 \%$ decrease evident at $4.5 \mathrm{~h}$ and $8.5 \mathrm{~h}(\mathrm{p}<0.01)$. The tendency for VLDL2 apo B to fall was also noted in the normoglycaemic clamp. Normal subjects showed little alteration in VLDL2 apo B levels.

VL D L 1 and VL D L 2 apo B production. Inspection of the tracer $\left[3-{ }^{2} \mathrm{H}\right]$-leucine mass $(\mathrm{mg})$ curves (Fig. 2) for VLDL1 and VLDL2 apo B revealed that insulin administration had less effect in NIDDM than in normal subjects despite the fact that normal subjects and patients with NIDDM had similar plasma lipid levels (Table 1) and VLDL1 and VLDL2 apo B pool sizes (Tables 2 and 3). When the model in Figure 1 was applied to the data it was found that the initial VLDL1 apo B production rate $(729 \pm 94 \mathrm{mg} /$ day) was similar to that seen earlier in normal subjects (Table 4). A non-steady-state analysis was essential in the normal study [8] to generate an acceptable fit of the model to the observed data because of the fall in the pool size (Table 2). VLDL1 apo B production is therefore changing all the time and for ease of comparison kinetic parameters at $4.5 \mathrm{~h}$ are used for testing for differences. In normal subjects, insulin infusion was associated with a reduction in VLDL1 apo B production (Table 4) but in the NIDDM patients in the present study, insulin administration in either the hyperglycaemic or normoglycaemic turnover did not significantly perturb VLDL1 apo B production rates at $4.5 \mathrm{~h}$ (Table 4). Similarly, after $8.5 \mathrm{~h}$ of infusion VLDL1 apo B production was $701 \pm 102,672 \pm 94$ and $603 \pm 145 \mathrm{mg} /$ day during the saline infusion, hyperglycaemic and normoglycaemic clamps, respectively. This represents an inhibition of VLDL1 apo B production of only $7 \pm 7$ and $3 \pm 8 \%$ (NS each) at 4.5 and $8.5 \mathrm{~h}$ of 
Table 4. The synthetic rates of VLDL1 and VLDL2 apo B (mg/day)

\begin{tabular}{|c|c|c|c|c|c|c|c|c|c|}
\hline \multirow[t]{2}{*}{ Subject } & \multicolumn{3}{|c|}{ VLDL1 synthesis } & \multicolumn{3}{|c|}{ VLDL2 input from VLDL1 } & \multicolumn{3}{|c|}{ VLDL2 direct synthesis } \\
\hline & Saline & Ins $A$ & Ins B & Saline & Ins A & Ins B & Saline & Ins A & Ins B \\
\hline 1 & 507 & 326 & 269 & 507 & 326 & 269 & 188 & 108 & 210 \\
\hline 3 & 687 & 792 & 870 & 687 & 792 & 870 & 175 & 155 & 166 \\
\hline 4 & 500 & 510 & 331 & 483 & 492 & 311 & 191 & 179 & 230 \\
\hline 5 & 904 & 842 & & 356 & 796 & & 116 & 72 & \\
\hline 6 & 690 & 625 & 747 & 690 & 625 & 747 & 140 & 106 & 92 \\
\hline Control subjects & $719 \pm 80$ & $385 \pm 90^{\mathrm{a}}$ & & $641 \pm 88$ & $339 \pm 61^{\mathrm{a}}$ & & $269 \pm 35$ & $265 \pm 37$ & \\
\hline
\end{tabular}

Ins A under hyperglycaemic conditions in patients with NIDDM; Ins B under normoglycaemic conditions in patients with NIDDM; Numbers represent the values calculated from the kinetic parameters at $4.5 \mathrm{~h} .{ }^{\mathrm{a}} \mathrm{p}<0.05$ as compared to saline infusion

Table 5. The catabolic rates of VLDL1 and VLDL2 apo B (pools/day)

\begin{tabular}{|c|c|c|c|c|c|c|}
\hline \multirow[t]{2}{*}{ Subject } & \multicolumn{3}{|c|}{ VLDL1 FCR } & \multicolumn{3}{|c|}{ VLDL2 FCR } \\
\hline & Saline & Ins A & Ins B & Saline & Ins $A$ & Ins B \\
\hline 1 & 5.3 & 4.0 & 5.0 & 5.1 & 4.2 & 5.8 \\
\hline 2 & 6.1 & 4.8 & 7.0 & 7.3 & 7.0 & 7.2 \\
\hline 4 & 13.9 & 14.9 & 28.4 & 6.8 & 7.6 & 8.0 \\
\hline 5 & 6.3 & 16.8 & & 3.6 & 3.9 & \\
\hline 6 & 7.2 & 5.4 & 5.2 & 5.8 & 5.4 & 5.8 \\
\hline
\end{tabular}

Ins A under hyperglycaemic conditions in patients with NIDDM, Ins B under normoglycaemic conditions in patients with NIDDM; Numbers represent the values calculated from the kinetic parameters at $4.5 \mathrm{~h}$; FCR, fractional catabolic rate

insulin infusion during the hyperglycaemic clamp compared to the saline control. This is in contrast to the $46 \pm 10$ and $50 \pm 15 \%$ inhibition (both $p<0.05$ ) observed at 4.5 and $8.5 \mathrm{~h}$ insulin infusion in normal subjects (Table 4).

In patients with NIDDM direct input of VLDL2 apo B (Table 4) was $19 \%$ lower during the hyperglycaemic hyperinsulinaemic study $(137 \pm 20 \mathrm{mg} /$ day $)$ compared to saline study $(169 \pm 14 \mathrm{mg} / \mathrm{day}, \mathrm{p}<0.05)$. Input of apo B from VLDL1 to VLDL2 (Table 4) was similar in hyperglycaemic (674 $\pm 100 \mathrm{mg} /$ day) and normoglycaemic $(616 \pm 135 \mathrm{mg} /$ day $)$ clamp and saline infusion study $(635 \pm 104 \mathrm{mg} /$ day $)$. In normal subjects acute hyperinsulinaemia did not change VLDL2 apo B production but decreased apo B input from VLDL1 to VLDL2 (Table 4).

Fractional catabolic rates of VL D L 1 and VL D L 2 apo $B$. In patients with NIDDM fractional catabolic rates (FCR) of VLDL1 and VLDL2 apo B (Table 5) were similar during the hyperglycaemic hyperinsulinaemia $(8.6 \pm 2.3$ and $5.5 \pm 0.6$ pools/day), normoglycaemic hyperinsulinaemia (11.0 \pm 4.4 and $6.2 \pm 0.7$ pools/ day) and saline infusion study (7.6 \pm 1.3 and $5.6 \pm 0.5$ pools/day), although there was considerable interindividual variation in the response to insulin. The mean FCR values of normal subjects were comparable (Table 5).

\section{Discussion}

NIDDM subjects in the present study were chosen to have plasma triglyceride and VLDL levels in the range of normal subjects examined earlier in whom we were able to demonstrate a specific effect of insulin on VLDL1 apo B metabolism. The principal finding was that in contrast to the substantial $40-50 \%$ suppression in VLDL1 apo B release seen in normal subjects, NIDDM subjects failed to exhibit a decrement in VLDL1 apo B production when challenged with an insulin infusion. VLDL1 apo B production which initially occurred at the same rate in normal subjects and NIDDM patients continued unaffected by insulin in either the hyperglycaemic or normoglycaemic clamp despite a profound reduction in plasma NEFA levels (Fig. 4). These data indicate that a component of insulin resistance is the failure in the liver to suppress the release of triglyceride-rich VLDL. This discovery has considerable implications for understanding triglyceride metabolism and the link between NIDDM and coronary heart disease risk.

On the basis of earlier studies in animals and man it was suggested that high insulin levels promoted release of VLDL from the liver, i. e. insulin stimulated the assembly and secretion of the lipoprotein [27, 28]. However, more recent cell culture work has provided clear evidence that the presence of insulin has 

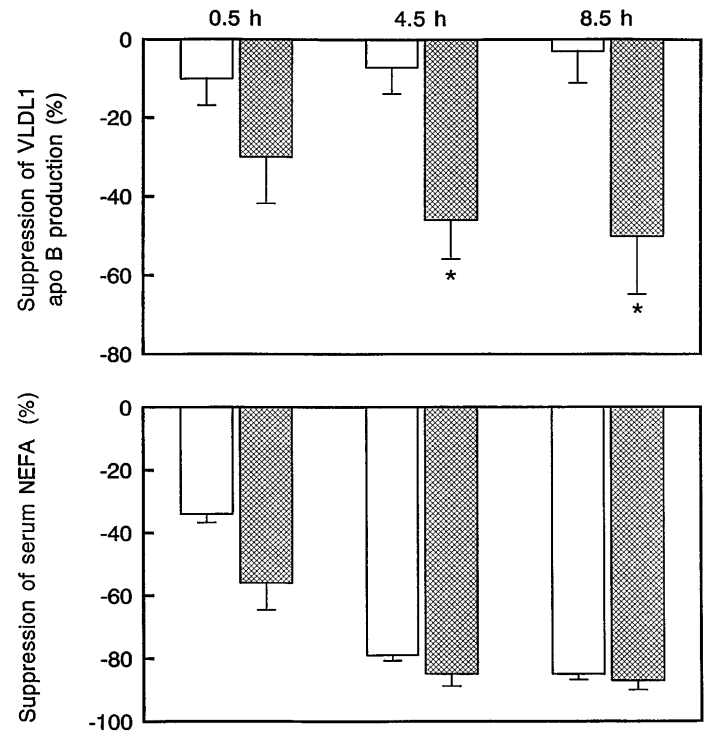

Fig. 4. The suppression of VLDL1 apo B production (upper panel) and serum NEFA concentration (lower panel) during infusion of insulin compared to infusion of saline in patients with NIDDM during hyperglycaemic clamp $(\square)$ and in normal subjects $\left({ }^{2}\right)$. Bars represent SEM. $* p<0.05$ between patients with NIDDM and normal subjects

an inhibitory effect on VLDL synthesis and release $[29,30]$. Comparable investigations in humans have reported discrepant results. In keeping with the present findings, Lewis et al. [6] found impaired suppression by insulin of total VLDL apo B production in insulin resistant obese women, whose fasting plasma triglyceride was $1.30 \pm 1.03 \mathrm{mmol} / \mathrm{l}$. By contrast Cummings et al. [9] reported, in a study with a design similar to ours, a decrease in VLDL apo B production during a hyperinsulinaemic, normoglycaemic clamp. This difference in outcome is likely due to patient selection and important differences in technique. First Cummings et al. included both normo- and hypertriglyceridaemic subjects and the latter may respond more readily to insulin. Second, they used a prolonged infusion of $13 \mathrm{~h}$ of a high dose of insulin $\left(1.0 \mathrm{mU} \cdot \mathrm{kg}^{-1} \cdot \mathrm{min}^{-1}\right)$. It is possible that more severe hypertriglyceridaemia may modulate the effect of insulin on VLDL apo B production. Indeed a more profound fall in VLDL apo B secretion rate was observed in hypertriglyceridaemic subjects with NIDDM [9]. We speculate that the variability of available lipid pool in the liver may influence VLDL apo $\mathrm{B}$ production and insulin action.

The in vivo findings of the present and previous [7] studies concur with the suggestion from cell culture work that there may be two separate mechanisms by which insulin regulates plasma triglyceride metabolism. VLDL secretion in hepatocytes is known to be stimulated by the amount of fatty acid delivered to cells and also to be inhibited by insulin in a manner which increases cellular triglyceride deposits [31-33] and possibly promotes intracellular apo B degradation. Both normal and NIDDM subjects respond to an insulin challenge by rapidly decreasing plasma NEFA levels but it may take a period of time before liver stores of triglyceride are depleted sufficiently to reduce VLDL secretion. We postulate that a more direct, central effect of the hormone is to shut down the synthesis of large triglyceride-rich VLDL (VLDL1), an action which fails to occur in insulin resistant subjects. The precise site of action of the hormone in the liver is unknown, possibilities include inhibition of microsomal transfer protein activity but this is thought to be a slow change [34] or more likely a suppression of the release of triglyceride from cytoplasmic stores. However it works, insulin has a specific influence on VLDL1 secretion leaving the VLDL2 unchanged. It is possible that the hormone interferes with the postulated second step of VLDL assembly, i.e. the fusion of a triglyceride droplet with a small nascent VLDL particle at the junction of the smooth and rough endoplasmic reticulum [35] by suppressing the formation of the droplet from cell triglyceride deposits.

Production of VLDL2 apo B was lower in NIDDM patients than in normal subjects during the saline and insulin infusions. This finding confirms a similar observation made in earlier study using radioiodinated tracers in which the VLDL1 and VLDL2 apo $\mathrm{B}$ production rates were $811 \pm 233$ and $182 \pm$ $253 \mathrm{mg} /$ day respectively [12]. We observed a small decrease in VLDL2 apo B production during the hyperglycaemic clamp. Thus insulin may have a direct effect on VLDL2 apo B production. However, in our NIDDM subjects insulin has no consistent effect on VLDL1 apo B synthesis or VLDL2 apo B input from VLDL1 apo B that are major determinants of VLDL2 apo B pool size. It may be that in long-standing insulin resistance direct VLDL2 apo B synthesis is defective and perturbed by exogenous insulin infusion. The mechanism underlying reduced secretion of VLDL2 apo B in NIDDM is not clear. In a recent study [36] it has been shown that VLDL2 apo B production is increased in hypercholesterolaemics and may be a function more of hepatic cholesterol than triglyceride metabolism. In this regard it is of interest to note that the absorption of dietary cholesterol, and hence the delivery of this sterol to the liver, is reported to be inefficient in NIDDM [37]. This in turn may limit the amount of sterol, in particular cholesterol ester, available for VLDL2 production.

From the appearance of the curves in normal subjects and from the modelling approach it was clear that there was no change in FCR of VLDL1 apo B during insulin infusion. Some NIDDM patients on insulin had increase of VLDL1 apo B FCR as in subjects 3, 4 and 5 and the model was able to quantify this; however, this finding was not consistent. In line with this Cummings et al. [9] observed no effect of insulin on VLDL apo B FCR in NIDDM subjects. 
In conclusion, we have uncovered an action of insulin on VLDL1 apo B metabolism in vivo that was postulated to occur on the basis of cell culture findings [29, 30]. Teleologically, an acute action of insulin on the release of large triglyceride-rich lipoproteins from the liver helps preserve hepatic lipid stores at a time when there is abundant triglyceride present in the circulation in the form of chylomicrons i.e. it is a further 'anabolic' action of the hormone. The impairment of this action in insulin-resistant subjects may be the root cause of their characteristic hypertriglyceridaemia and hence other lipoprotein abnormalities, although increased NEFA transport from adipose tissue to the liver also plays a role $[38,39]$. The rate of inhibition of VLDL1 apo B release by insulin in normal subjects of $9 \%$ per hour [8] indicates that this phenomenon can contribute to the regulation of triglyceride-rich lipoproteins postprandially. Failure to suppress VLDL1 release is likely to contribute to the excessive post-prandial lipaemia seen in NIDDM [40], a suggested independent risk factor for coronary heart disease [41]. VLDL1 can therefore be viewed as the liver's chylomicron and the balance between intestinal and gut-derived triglyceride-rich lipoproteins in the circulation as an additional function of insulin.

A cknowledgements. The skillful technical assistance of Ms. A. Salo, Ms. S. Rannikko and Ms. H. Perttunen-Nio is greatly appreciated. We thank Ms. S. Aarnio for drawing the figures and Ms. N. Thompson for helping in manuscript preparation.

This study was supported by grants from Sigrid Juselius Foundation, Helsinki, Finland and from British Heart Foundation.

\section{References}

1. Taskinen M-R (1995) Insulin resistance and lipoprotein metabolism. Curr Opin Lipidol 6: 153-160

2. Nikkilä EA, Kekki M (1973) Plasma triglyceride transport kinetics in diabetes mellitus. Metab Clin Exp 22: 1-22

3. Taskinen M-R, Belz WF, Harper I et al. (1986) Effects of NIDDM on very-low-density lipoprotein triglyceride and apolipoprotein B metabolism. Studies before and after sulfonylurea therapy. Diabetes 35: 1268-1277

4. Kissebah AH, Alfarsi S, Evans DJ, Adams PW (1982) Integrated regulation of very low density lipoprotein triglyceride and apolipoprotein-B kinetics in non-insulin-dependent diabetes mellitus. Diabetes 31: 217-225

5. Cummings MH, Watts GF, Umpleby AM et al. (1995) Increased hepatic secretion of very-low-density lipoprotein apolipoprotein B-100 in NIDDM. Diabetologia 38: 959967

6. Lewis GF, Uffelman KD, Szeto LW, Steiner G (1993) Effects of acute hyperinsulinaemia on VLDL triglyceride and VLDL ApoB production in normal weight and obese individuals. Diabetes 42: 833-842

7. Lewis GF, Uffelman KD, Szeto LW, Weller B, Steiner G (1995) Interaction between free fatty acids and insulin in the acute control of very low density lipoprotein production in humans. J Clin Invest 95: 158-166
8. Malmström R, Packard CJ, Watson TDG et al. (1997) Metabolic basis of hypotriglyceridemic effects of insulin in normal men. Arterioscler Thromb Vasc Biol. (In press)

9. Cummings MH, Watts GF, Umpleby AM et al. (1995) Acute hyperinsulinaemia decreases the hepatic secretion of very-low-density lipoprotein apolipoprotein B-100 in NIDDM. Diabetes 44: 1059-1065

10. DeFronzo RA, Tobin JD, Andres R (1979) Glucose clamp technique: a method for quantifying insulin secretion and resistance. Am J Physiol 237(3):E214-E223

11. Mokan M, Gerich JE (1992) A simple insulin infusion algorithm for establishing and maintaining overnight near-normoglycemia in type I and type II diabetes. J Clin Endocrinol Metab 74: 943-945

12. Taskinen M-R, Packard CJ, Shepherd J (1990) Effect of insulin therapy on metabolic fate of apolipoprotein B-containing lipoproteins in NIDDM. Diabetes 39: 10171027

13. Lindgren FT, Jensen LC (1972) The isolation and quantitative analysis of serum lipoproteins. In: Nelson GJ (ed) Blood lipids and lipoproteins: Quantitation, composition and metabolism. John Wiley \& Sons, Livermore, California, pp 182-217

14. James RW, Martin B, Pometta D et al. (1989) Apolipoprotein B metabolism in homozygous familial hypercholesterolemia. J Lipid Res 30: 159-169

15. Hardman DA, Kane JP (1986) Isolation and characterisation of apolipoprotein B-48. In: Segrest JP, Albers JJ (eds) Methods in enzymology. Plasma lipoproteins (Part A): Preparation, structure and molecular biology, 128. Academic Press, Orlando, pp 247-262

16. Egusa G, Brady DW, Grundy SM, Howard BV (1983) Isopropanol precipitation method for the determination of apolipoprotein B specific activity and plasma concentrations during metabolic studies of very low density lipoprotein and low density lipoprotein apolipoprotein B. J Lipid Res 24: 1261-1267

17. Demant T, Packard CJ, Demmelmair H et al. (1996) Sensitive methods to study human apolipoprotein B metabolism using stable isotope-labeled amino acids. Am J Physiol 270:E1022-E1036

18. CONSAM user's manual for CONSAM version 30 (1990) In: Resource facility for kinetic analysis. Department of Bioengineering. University of Washington, Seattle

19. Björkegren J, Packard, CJ, Hamsten A et al. (1996) Accumulation of large very low density lipoprotein in plasma during intravenous infusion of a chylomicron-like triglyceride emulsion reflects competition for a common lipolytic pathway. J Lipid Res 37: 76-86

20. Kadish AH, Litle RL, Sternberg JC (1968) A new and rapid method for the determination of glucose by measurement of rate of oxygen consumption. Clin Chem 14: 116131

21. Cole RA, Soeldner JS, Dunn PJ, Bunn HF (1978) A rapid method for the determination of glycosylated hemoglobins using high pressure liquid chromatography. Metabolism 27: 289-301

22. Miles J, Glasscock R, Aikens J, Gerich J, Haymond M (1983) A microfluorometric method for the determination of free fatty acids in plasma. J Lipid Res 24: 96-99

23. Roberts I, Smith IM (1986) A simple method for the measurement of glycerol in serum. Ann Clin Biochem 23: 490491

24. Kashyap ML, Hynd BA, Robinson K (1980) A rapid and simple method for measurement of total protein in very low density lipoproteins by the Lowry assay. J Lipid Res 21: 491-495 
25. Havekes LM, Knijff de P, Beisiegel U, Havinga J, Smit M, Klasen E (1987) A rapid micromethod for apolipoprotein E phenotyping directly in serum. J Lipid Res 28: 455-463

26. Rising R, Swinburn B, Larson K, Ravussin E (1991) Body composition in Pima Indians: validation of bioelectrical resistance. Am J Clin Nutr 53: 594-598

27. Reaven GM (1987) Abnormal lipoprotein metabolism in non-insulin-dependent diabetes mellitus. Pathogenesis and treatment. Am J Med 83[Suppl 3A]:31-40

28. Steiner G, Haynes FJ, Yoshino G, Vranic M (1984) Hyperinsulinaemia and in vivo very-low-density lipoprotein-triglyceride kinetics. Am J Physiol 246:E187-E192

29. Sparks CE, Sparks JD, Bolognino M, Salhanic A, Strumph PS, Amatruda JM (1986) Insulin effects on apolipoprotein B lipoprotein synthesis and secretion by primary cultures of rat hepatocytes. Metabolism 35: 1128-1136

30.Salhanick AI, Schwartz SI, Amatruda JM (1991) Insulin inhibits apolipoprotein B secretion in isolated human hepatocytes. Metabolism 40: 275-279

31. Dashti N, Wolfbauer G (1987) Secretion of lipids, apolipoproteins, and lipoproteins by human hepatoma cell line, HepG2: effects of oleic acid and insulin. J Lipid Res 28: 423-436

32. Dixon JL, Furukawa S, Ginsberg HN (1991) Oleate stimulates secretion of apolipoprotein B-containing lipoproteins from Hep $\mathrm{G} 2$ cells by inhibiting early intracellular degradation of apolipoprotein B. J Biol Chem 266: 5080-5086

33. Byrne CD, Wang TWM, Hales CN (1992) Control of Hep G2-cell triacylglycerol and apolipoprotein B synthesis and secretion by polyunsaturated non-esterified fatty acids and insulin. Biochem J 288: 101-107

34. Lin MCM, Gordon D, Wetterau JR (1995) Microsomal triglyceride transfer protein (MTP) regulation in HEPG2 cells: insulin negatively regulates MTP gene expression. J Lipid Res 36: 1073-1081

35. Dixon JL, Ginsberg HN (1993) Regulation of hepatic secretion of apolipoprotein B-containing lipoproteins: information obtained from cultured liver cells. J Lipid Res 34: 167-179

36. Gaw A, Packard CJ, Lindsay GM et al. (1995) Overproduction of small very low density lipoproteins (Sf 20-60) in moderate hypercholesterolemia: relationship between apolipoprotein B kinetics and plasma lipoproteins. J Lipid Res 36: $158-171$

37. Gylling H, Miettinen TA (1994) Serum cholesterol and cholesterol and lipoprotein metabolism in hypercholesterolaemic NIDDM patients before and during sitostanol ester-margarine treatment. Diabetologia 37: 773-780

38. Castro Cabezas M, de Bruin TWA, de Valk HW, Schoulders CC, Jansen H, Erkelens DW (1993) Impaired fatty acid metabolism in familial combined hyperlipidemia; a mechanism associating hepatic apolipoprotein B overproduction and insulin resistance. J Clin Invest 92: 160-168

39. Björntorp P (1994) Fatty acids, hyperinsulinaemia and insulin resistance: which comes first. Curr Opin Lipidol 5: 166-174

40. Syvänne M, Hilden H, Taskinen M-R (1994) Abnormal metabolism of postprandial lipoproteins in patients with non-insulin-dependent diabetes mellitus is not related to coronary artery disease. J Lipid Res 35: 15-26

41. Patsch JR, Miesenböck G, Hopferwieser Tet al. (1992) Relation of triglyceride metabolism and coronary artery disease. Studies in the postprandial state. Arterioscler Thromb 12: 1336-1345 